\title{
Shigella and Salmonella, Antibiotics Susceptibility Pattern and Associated Risk Factors among Diarrheic Children in Southern Ethiopia: a cross sectional study
}

\section{Manamo Hayamo}

Hawassa University College of Natural and Computational Science

Tsegaye Alemayehu ( $\sim$ alemayehutsegaye@ymail.com )

https://orcid.org/0000-0001-7579-8991

Bereket Tadesse

Hawassa University College of Medicine and Health Sciences

Enkusilasie Mitiku

Hawassa University College of Medicine and Health Sciences

\section{Zufan Bedawi}

Hawassa University College of Natural and Computational Science

\section{Research}

Keywords: Salmonella, Shigella, Diarrhea, Antibiotics resistance, Children, Southern Ethiopia

Posted Date: January 29th, 2020

DOl: https://doi.org/10.21203/rs.2.22226/v1

License: (c) (1) This work is licensed under a Creative Commons Attribution 4.0 International License.

Read Full License 


\section{Abstract}

Background: Salmonella and Shigella is a major health problem worldwide, in developing countries like Ethiopia, it is responsible for high morbidity and mortality of children. This study aimed to determine the prevalence of Salmonella and Shigella infection, their antibiotic susceptibility pattern and associated risk factor among the diarrheic pediatrics patients that visited Alamura Health Center in southern Ethiopia.

Method: A facility based cross-sectional study was conducted at Alamura Health Center from April 2018 - July 2019. The study was performed on pediatrics below the age of 14 years in which consecutive children with diarrhea were included for the study. A structured questionnaire was used to collect sociodemographic and clinical data after assent and consent obtained from parents or care taker. The stool sample cultured as per the standard operating procedure (SOP) of the microbiology laboratory. Antibiogram was performed by Kirby-Bauer disc diffusion method and was interpreted based on the Clinical and laboratory standard institute guidline (CLSI) version 2018.

Results: Out of 263 children enrolled in the study, $50.5 \%$ were females. The overall, 21/263 (8\%) $95 \% \mathrm{Cl}$, (4.6 - 11.4\%) Shigella and Salmonella was isolated. Shigella dysenteriae was dominantly isolated 11 (4.2\%) followed by $9(3.42 \%)$ Shigella spp, and $1(0.38 \%)$ Salmonella typhi. Those with habit of washing the hands of children after toilet sometimes $(A O R=235.1,95 \% \mathrm{Cl}, 20.9-2643.3, \mathrm{P}=.000)$ and store cooked food in open container for later use $(A O R=36.44,95 \% \mathrm{Cl}, 5.82-228.06, \mathrm{P}=.000)$ showed statistically significant association.

Conclusion: High level of Shigella spp and one Salmonella was isolated from diarrheic children at Alamura Health Center. Shigella dysentery was the most dominantly isolated. Those practised hands wash for their child after defecation for sometimes was 235.1 -fold at risk of infection. Similarly, those store foods for later use in an open container was 36.44 times at risk of infection. Therefore, to alleviate this infection the concerned body should focus on giving health education for hand wash after defecation and storing food in a closed container later use is mandatory.

\section{Background}

Diseases caused by the enteric pathogens are common public health problems in many parts of the world including Ethiopia[1, 2]. Salmonella and Shigella are associated with a high burden of illness among children in the developing world [3]. Children are one of the victims to these infections accounting for approximately 8 per cent of all deaths among children under age 5 worldwide in 2017. This interpreted to over 1,300 young children passed away each day, 480,000 children a year, regardless of the availability of humble active treatment. Most of these deaths due to diarrhea is in South Asia and sub-Saharan Africa [4]. Studies in Ethiopia from different regions reported that 4.3-17-45\%[5-8] Shigella and 1-12.6 \%[6-8] Salmonella infection was confirmed.

They are species of particular concerns as causes of enteric fevers, food poisoning and gastroenteritis [9]. They are Gram-negative rods which commonly inhabit intestinal tracts of humans and many animals 
[10]. It was estimated worldwide about 1.8 million cases of children died from diarrheal illness, a large proportion of which were attributed to Shigella and Salmonella spp.[11]. Different studies have reported that Shigella Spp. were associated with the majority of cases of bacillary dysentery which is prevalent mainly in developing nations. Whereas, Salmonella spp. were the most common cause of food-borne infection out breaks in almost allover the world [12]. In recent year the emergence and global dissemination of Salmonella and Shigella species resistance to ampicillin, chloramphenicol, tetracycline and co-trimoxazole increasingly documented in developing countries [13].

Infections of Shigella and Salmonella can be asymptomatic and can be treated with rehydration solutions unless the infection is by invasive strains [14]. Prescribing antibiotics might shorten the extent of diarrhea and control the shedding of the organisms which otherwise might continue to spread among people and in to the environment and further pose a risk of spread of infections [15]. Children are at high risk of these infections due to their weekend immune status and ease of contamination[16]. In developing countries, this increased due to poor sanitation, personal hygiene and lack of appropriate food supply that leads children to contaminate themselves [17]. Therefore, this study aimed to identify Shigella and Salmonella infections, their antibiotics susceptibility and associated risk factors among children with diarrhea that visited Alamura health center.

\section{Method And Materials}

\section{Study Area and Period}

The study was conducted in the southern nation, nationalities and peoples region (SNNPR) at Hawassa Alamura Health Center. Hawassa is the capital city of Southern Nation Nationality People Region (SNNPR), located in the Southern part of Ethiopia, on the shores of Lake Hawassa which is one of the Great Rift Valley lakes and $270 \mathrm{~km}$ from the capital city of Ethiopia. Mean annual rainfall of about 950 $\mathrm{mm}$, the temperature of $20^{\circ} \mathrm{C}$ and humidity of $70 \%-80 \%$. The mean rainy season generally extends from June to october [18], gives the estimated population of Hawassa for 2015 as 351,469 , with annual population growth, rate of just over $4 \%$. The Hawassa city has seven sub cities with five privates, one general and one comprehensive specialized Hospital and ten health centers. Alamura Health Centers was located in the Tabor sub-city and borderline between Fara and Hitata kebele near Alamura Mountain.

\section{Study Design and population}

Facility based cross-sectional study was conducted at Alamura Health Center. A convenient sampling technique was employed in which diarrheic pediatrics patients that their family or guidance is volunteer to participate in the study were consecutively included until the calculated sample size was achieved. All diarrheic pediatrics patients that were visited Alamura Health Center for the diarrheal case of illness. Selected diarrheic pediatrics patient that visited Alamura Health Center during the study period was the study population. Pediatrics patients under 14 years of age whom his/her parents or guardians 
consented for the participation of the study included for the study. That parents/caretaker are involuntary to sign consent and pediatrics refuse for assent excluded from the study.

\section{Variable of the Study}

The dependent variables were the presence of Salmonella and Shigella and the independent variables were: sociodemographic factors that is age, sex, place of residence, educational status of the mothers, marital status, family size, monthly income, occupation of family and clinical and behavioral factors (previous history of diarrhea, type of diarrhea, source of drinking water, washing of child hand after toilet, food/drink taken before illness, storage of cooked food for later use, habit of hand washing before and after meal, washing habit of food containers, history of malnutrition and history of contact with domestic animals) were assessed with structured questionnaire.

\section{Data Collection}

The socio-demographic and clinical data collected after the parents/ caregiver informed about the aim of the study. Face-to-face interview conducted to collect the data with a structured questionnaire from parents or caretaker of the children who complained of diarrhea after they signed the consent and the child accepted the assent.

\section{Laboratory diagnosis}

The stool was collected using a screw cup container. The parents/caregiver instructed to bring a fresh stool sample before 30 minutes of collection and avoid contamination with urine and other materials. All stool specimens placed into Carry Blair transport medium \& transported to the microbiology laboratory of Hawassa University Comprehensive Specialized Hospital (HUCSH). The stool was inoculated on prepared culture media that is MacConkey, Xylose lysine deoxycholate (XLD) and selenite F-broth (Abtek, UK). The culture plates incubated aerobically at $37^{\circ} \mathrm{C}$ for 24 hours.

\section{Bacterial identification}

The colonies examined morphologically for size, shape, and ability to ferment lactose. Those bacterial colonies with non-lactose fermenting characteristics with $\mathrm{H}_{2} \mathrm{~S}$ for Salmonella and without $\mathrm{H}_{2} \mathrm{~S}$ for Shigella picked for biochemical identification. Indole test, urease production, mannitol fermentation, hydrogen sulphide, gas production test, citrate utilization test, motility test, carbohydrate fermentation test, lysine decarboxylase test (LDC) and oxidase test were used to differentiate to genus and species level [19].

\section{Antibiotics susceptibility testing}

A pure colony of isolated bacteria was mixed with normal saline to make a 0.5 McFarland standards suspension for susceptibility testing then swabed on Mueller Hinton agar. The suspetebility pattern of the isolates wer determined for ciprofloxacin-CIP $(5 \mu \mathrm{g})$, augmentin -AUG $(30 \mu \mathrm{g})$, gentamicin - GEN $(10 \mu \mathrm{g})$, 
chloramphenicol - CAF $(30 \mu \mathrm{g})$, co-trimoxazoale-COT $(25 \mu \mathrm{g})$, tetracycline - TAT $(30 \mu \mathrm{g})$, ampicillin - AMP (

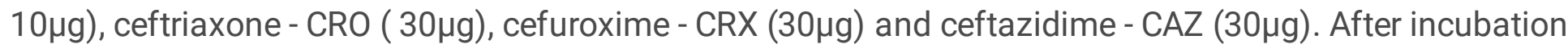
for 24 hours at $37 C^{0}$, the diameter of each zone of inhibition was measured with a rular in mm. The results then interpreted according to CLSI guidelines antimicrobial susceptibility breaking points 2018 and recorded as sensitive $(S)$, intermediate $(I)$ or resistance $(R)$ [19].

\section{Data analysis}

Data was entered to statistical package for the social science (SPSS) versions 20 and was analyzed to make inferences on the frequency of occurrence of enteric pathogens associated with diarrhea and to show bacterial resistance pattern to locally prescribe antibiotic substances. Descriptive statistics were performed to get the frequency of dependent and independent variables. Binary logistic regression analysis was conducted to identify real pridector of Shigella and Salmonella. The strength of association was presented by odds ratio at $95 \%$ confidence interval and $p$ - value $\leq 0.05$ was considered as a statistically significant association.

\section{Ethical Consideration}

The study was conducted after formal permission was obtained from Southern Nation Nationality and People Regional Health Office, Hawassa city administration health office, Alamura Health center manager and laboratory head. The patients were included in the study if their parents or care taker sign the consent. Culture results and antimicrobial susceptibility results were communicated to the concerned bodies of in health center within 72 hrs and treatmented accordingly.

\section{Result}

\section{Socio-demographic characteristics}

A total of 263 diarrheic pediatric patients from Alamura Health Center was enrolled for the study with a mean and standard deviation of age $6.8 \pm 3.7$ years. The frequency and percentage of pediatrics age range enrolled for the study were, 0-4, 88(33.5\%), 5-9, 103(39.2\%) and 10-14, 72 (27.4\%). The almost equal ration of male to female enrolled for the study (130:133). Regarding the residence, most of the study subjects 155(58.9\%) were from Urban area and 108(41.1) was from rural. Concerning the pediatrics' mother educational status most of them (81\%) were educated which was included from reading and writing to university graduate level the rest $19 \%$ are illiterates. The marital status of their mother 178 (67.7\%) was married, 43(16.3\%) divorced and 41(15.6\%) widowed. The mean and standard deviation of the family size was $5.6 \pm 1.9$ persons. The average income of the family was $3743.3 \pm 2568.1$ Ethiopian birr. Most of the study participants have a large family size with relatively low income earned $<1500$ birr per month from this number diarrhea positive was 12(57.1\%) (Table 2).

\section{The magnitude of Shigella and Salmonella}


The overall magnitude of Shigella and Salmonella among diarrheic pediatrics patients in Alamura Health Center was 8.0\% (21/263) 95\% Cl (4.6-11.4\%). Shigella Spp isolated from 7.6\% (20/263) $95 \% \mathrm{Cl}[4.6-11.0]$ of children. Shigella dysentery was frequently isolated from $4.2 \%(11 / 263) 95 \% \mathrm{Cl}[1.9-6.8]$ followed by other Shigella spp 3.42\% (9/263), 95\% Cl [1.5 -5.7] and Salmonella spp 0.4\% (1/263) 95 \% Cl [.0-1.1]. In the rest, $92 \%$ (242/263) diarrheic pediatrics patients' Shigella and Salmonella were not isolated (Fig.1).

\section{Antimicrobial susceptibility pattern}

\section{Salmonella typhi}

There was only one Salmonella typhi isolated. It was sensitive for ciprofloxacin, gentamicin, ceftazidime, chloramphenicol, cefuroxime, ceftriaxone and co-trimoxazole and resistance for ampicillin and tetracycline.

\section{Other Shigella species}

Shigellaspp isolate was $100.0 \%$ senstive to both ceftriaxone and ciprofloxacin, $77.8 \%$ for both ceftazidime and chloramphenicol, were as $66.7 \%$ for cefuroxime and $55.6 \%$ for gentamycin. Resistance was seen $81.8 \%$ for ampicillin, $72.7 \%$ for tetracycline, and $55.6 \%$ for both co-trimoxazole and augmentin.

\section{Shigella dysentery}

Shigella dysentery isolate was $100 \%$ susceptible for gentamicin, $90.9 \%$ for ciprofloxacin, $90 \%$ for ceftazidime, $72 \%$ for both ceftriaxone and chloramphenicol. Resistance was seen $45.5 \%$ for ampicillin, $55 \%$ for co-trimoxazole, $72.7 \%$ for tetracycline and $91 \%$ for augmentin (Table 1 ).

\section{Associated risk factors}

Among the study participant, $162(61.6 \%)$ of them had a history of diarrhea, of this $17(81.0 \%)$ were positive for current infection. Of all diarrheic children, the type of diarrhea was watery for $111(42.2 \%)$, mucoid for 103(39.3\%) and bloody for 49(18.6\%). Children with mucoid diarrhea affected more that are $13(61.9 \%)$ as compared to the rest patients. Most of the children $170(64.6 \%)$ had diarrhea once in a day and most of the bacteria 11(52.4\%) was isolated form this patient. Most of the children used a piped water 159 (60.9\%), similarly, the children in these categories were infected more 17 (81.0\%).

Regarding hand wash, after defecation, most of the children practised hand wash after toilet always 221 (84.0\%) but those who practised hand wash sometimes was infected more 20 (95.2\%). Most of the food taken by the children before the illness was cooked food 82(31.2\%) even if the bacterial infection was dominantly isolated from children that feed overnight food 8(38.1\%). Most of the children enrolled for the study was those who store their food in closed container 223(84.8\%), lack habit of hand wash before and after meal $178(67.7 \%)$, had habit of washing of food container $157(59.7 \%)$, those are well-nourished $238(90.5 \%)$, those who had vaccinated $202(76.8 \%)$, and had animal contact 137(52.1\%).

Correspondingly, most of the bacteria were isolated from those who store food in an open container 
$16(76.2 \%)$, lack of habit of hand wash after or before meal 15 (71.4 \%), washing of food container for sometimes $17(81.0 \%)$, well-nourished $18(85.7 \%)$, vaccinated $14(66.7 \%)$ and had animal contacts 13(61.9\%) (Table 2).

The bivariate analyses indicates that family with monthly income $>1500$ (COR $=2.250,95 \% \mathrm{Cl}, 0.86$ $5.902, p=.099)$, educational status of mother that can able read and write $(\mathrm{COR}=5.170,95 \% \mathrm{Cl}, 0.62$ $43.05, p=.129)$, those had previous history of diarrhea (COR $=0.35,95 \% \mathrm{Cl}, 0.115-0.078, \mathrm{p}=.067)$, watery diarrheal type $(\mathrm{COR}=11.69,95 \% \mathrm{Cl}, 0.988-138.44, \mathrm{p}=.051)$, mucoid $(\mathrm{COR}=16.75,95 \% \mathrm{Cl}, 2.130$ $131.67, p=.007)$. Similarly, those who used pipe water source $(\mathrm{COR}=2.993,95 \% \mathrm{Cl}, 0.978-9.16, \mathrm{p}=$ $.055)$. Who wash the hands of their child sometime (COR=200.0,95\% $\mathrm{Cl}, 25.602-1562.348, \mathrm{p}=.000$ ). Store food in open containers (COR $=29.1,95 \% \mathrm{Cl}, 9.78-86.37, \mathrm{p}=.000)$ and had washing habit of food containers sometimes ( $\mathrm{COR}=7.306,95 \% \mathrm{Cl}, 2.38-22.4, \mathrm{p}=.001)$ was candidate variables for multivariable analysis with $p$ - value $\leq 0.25$ (Table 2).

However, in multivariate analysis, after adjustment, those who had a habit of washing the hands of children after toilet $(A O R=235.1,95 \% \mathrm{Cl}, 20.9-2643.3, \mathrm{P}=.000)$ and store cooked food in open container $(A O R=36.44,95 \% \mathrm{Cl}, 5.82-228.06, \mathrm{P}=.000)$ showed statistically significant association for Shigella and Salmonella infection with $\mathrm{p}$ - value $\leq .05$. However, factors like the type of diarrhea, history of contact with domestic animals, a habit of hand washing before and after a meal, and washing of food container were not statically significant associated factors (Table 3).

\section{Discussion}

Our study does not indicate the total prevalence of Salmonella and Shigella infection in Hawassa town. were, it does not identify bacteria at species level this was due to lack of anti-sera in the market. The study determined the prevalence of Shigella and Salmonella, their antibiotics susceptablity patern and associated risk factor among pediatric patient at Altamura Health Center.

The overall prevalence of Shigella and Salmonella isolated in this study was $8.0 \%$ [4.6 - 11.4\%] which is lower than compared with studies conducted in Tanzania 42.7\% [20], Mozambique 27.2\% [21], Ethiopia $22.3 \%$ [22] and $22.2 \%$ [23]. It is comparable with a study reported from Ethiopia 9.0\% [24] and 8.3\% [6]. The possible reason for such difference could be sample size, a method implemented and the age variation.

In this study $20(7.6 \%) 95 \% \mathrm{Cl}$ [4.6 -11.0] of Shigella spp was isolated which is comparable with a study conducted in Ethiopia $8.3 \%$ [6], 9.5\% [25], in contrast to our finding a lower rate of Shigella species was reported from China 1.4\% [26]. Our study tried to identify Shigella dysenteriae from other Shigella app with available biochemical tests accordingly 11 (4.2\%) $95 \%$ CI [1.9-6.8 \%] identified as Shigella dysenteriae. This rate is lower than a study reported from Nepal 14.5\% [27], 12\% Senegal. It is comparable with the finding from Central Africa $3 \%$ [28]. The other nine (3.42\%), 95\% Cl [1.5-5.7] was other species of Shigella was higher compared with results reported from China 1.4\% [26], Nigeria $1.4 \%$ [29], Ethiopia 1.3\% [30] and 1.1\% [31]. Our finding was lower than study reported from Jimma 20.1\% [32], 
Gondar 16.9\%[33], Bahir Dar 14.9\% [34], Harar 14.6 \% [35], Bahir Dar 9.5\% [36], Addis Ababa $9.1 \%$ [25], Iran 8.5\% [37], Southwest Ethiopia 8.4\% [38], Sudan 8\% [39], Bahir Dar 7.8\% [36], southern Ethiopia 7.0\% [23], Eastern Ethiopia 6.9\% [40] and Northern Ethiopia $6.9 \%$ [41]. This variation is may be due to the geographical location, climatic change and the age variation of participant. Comparable result was reported from Gondar $4.6 \%$ [42], Nepal $4.6 \%$ [43], Butajira 4.5\% [44] and 4.0\% Kenya[45], Turkey $3.2 \%$ [46], and Ethiopia 2.3\% [38].

A single S.typhi $0.4 \% 95 \% \mathrm{Cl}$ [0-1.1\%] was isolated in this study which is inline with the findings reported from the same country in Addis Ababa, $0 \%$ [30], $1.1 \%$ [42], in contrast to our finding higher rates was reported from Sudan 4.0\% [39], China 4.3 \% [26], Addis Ababa, Ethiopia 3.95\% [25], Kenya 3.4\% [45], Turkey 3\% [46], Gondar $1.6 \%[47]$, and Hawassa $1.5 \%$ [23]. This difference might be due to sample size, weather condition and study subjects age differences.

Our study revealed that the highest rates of antibiotic resistance of Shigella spps were against Ampicillin $81.8 \%$ which is comparable with the study reported from a different area of Ethiopia $70.1 \%$ from Jimma [32], $79.9 \%$ Gonder [48], 86.7\%[24], and $88.9 \%$ from Mekelle [49]. Our study also showed relatively low resistance compared to findings from Nigeria 90.5\% [50], Harar 100\% [40], Jimma 100\% [38], Hawassa $93 \%$ [33]. This may be due to widespread resistance strain throughout the countries. Another antibiotic resistance of Shigella spp was seen against tetracycline $71.4 \%$ and this was comparable with finding reported from Harar 70.6 \% [40], Jimma 63.6\% [32] and Mekelle 77.8\% [41]. The result was slightly lower than study reported from Butajira 82.4\% [44], Gondar 86\% [51] \& 86\% [48], Hawassa 90\% [33]. This may be due to those strains moderately susceptible for tetracycline at a certain corner of the country. Our result also indicated that $52.4 \%$ resistance was seen against co-trimoxazole and this was comparable with a study done in Hawassa 56.0\% [42], Addis Ababa 45.7\% [52] and Mekelle 55.6\% [41]. Inconstant to our finding higher result reported from Gonder $73.4 \%$ [48]. Several factors may contribute to resistance by pathogens causing gastroenteritis in developing countries like Ethiopia. These include frequent overuse, misuse and factors related to the potency and quality of antimicrobials and the distribution of resistant strains [52].

Our finding in the multivariate analysis showed that who had a habit of washing the hands of a child after toilet sometimes as compared to those practice hand washing always 235.1 times at risk of infection. Similarly, those who store cooked food in an open container for later use was 34.44 times at risk of infection as compared to those who practice closing of the container with $p$-value $\leq 0.05$ which is in agreement with a study conducted in Southern Ethiopia Arbaminch $[8,24,53]$.

\section{Conclusion}

Our study indicated that there was a high rate of Shigellosis among diarrheic pediatrics patients that visited Alamura Health Center during the study period and single Salmonella was isolated. The antimicrobial susceptibility test result showed that Shigella was highly resistant to ampicillin, tetracycline, augmentin and co-trimoxazole. Those practised hands wash for their child after defecation for 
sometimes was 235.1 -fold at risk of infection. Similarly, those store foods for later use in an open container was 36.44 times at risk of infection. Therefore, to alleviate this infection the concerned body should focus on giving health education for hand wash after defecation and storing food in a closed container later use is mandatory.

\section{Declarations}

Ethical Clearance: The study was conducted after formal permission was obtained from Southern Nation Nationality and People Regional Health Office, Hawassa city administration health office, Alamura Health center manager and laboratory head. The patients were included in the study if their parents or care taker sign the consent. Culture results and antimicrobial susceptibility results were communicated to the concerned bodies of in health center within $72 \mathrm{hrs}$ and treatmented accordingly.

Consent for publication: Not applicable

Availability of data and material: All the data supporting the findings can be obtained from the corresponding author.

Competing of interest: The authors declare that they have no competing interests

Funding: this study was partially supported for data collection by Hawassa University.

Authors' contribution:MH, TA,BT.EM, ZB equally conceived the idea, develop the proposal, collected the data, perform the analysis and prepared the manuscript, TA \& ZB has made a final edition of the document. All authors have read and approved the manuscript.

\section{Acknowledgements}

We would like to acknowledge Hawassa University, SNNPR health bureau, Alamura health center, and Hawassa university comprehensive specialized hospital for their co-operation and study participants at large.

\section{Legends}

Fig. 1 magnitude of Shigella Spp, Shigelladysentery and Salmonella typhi in diarrheic pediatrics patients from Alamura Health Center, southern Ethiopia, 2019.

Table 1 antimicrobial susceptibility profile of Salmonella species, Shigella spp and Shigella dysentetry isolated from diarrheric pediatrics patients in Alamura Health Center, South Ethiopia, 2019.

Table 2 bivariate analysis of socio-demographic characteristics and clinical data of diarrheic pediatrics patients in the Alamura Health Center, southern Ethiopia, 2019. 
Table 3 Multivariate analysis of associated risk factors for Shigella and Salmonella among pediatrics patient at Alamura Health Center, Southern Ethiopia, 2019.

\section{References}

1. Surafel k GKaAK: Prevalence of Shigella Related Diarrhea in Ambo Town and Antibiotic Susceptibility of the Isolated Strains. Greener Journal of Epidemiology and Public Health 2015, 3(1):001.

2. Troeger C, Khalil IA, Reiner RC: Estimating health-loss due to enteric pathogens: importance and challenges. The Lancet Global Health 2019, 7(3):e284-e285.

3. Kotloff KL, Nataro JP, Blackwelder WC, Nasrin D, Farag TH, Panchalingam S, Wu Y, Sow SO, Sur D, Breiman RF: Burden and aetiology of diarrhoeal disease in infants and young children in developing countries (the Global Enteric Multicenter Study, GEMS): a prospective, case-control study. The Lancet 2013, 382(9888):209-222.

4. women UDMtsoca: Diarrhoeal disease. https://datauniceforg/topic/child-health/diarrhoeal-disease/ 2019.

5. Alemu A, Geta M, Taye S, Eshetie S, Engda T: Prevalence, associated risk factors and antimicrobial susceptibility patterns of Shigella infections among diarrheic pediatric population attending at Gondar town healthcare institutions, Northwest Ethiopia. Trop Dis Travel Med Vaccines 2019, 5:7-7.

6. Abebe W, Earsido A, Taye S, Assefa M, Eyasu A, Godebo G: Prevalence and antibiotic susceptibility patterns of Shigella and Salmonella among children aged below five years with Diarrhoea attending Nigist Eleni Mohammed memorial hospital, South Ethiopia. BMC Pediatrics 2018, 18(1):241.

7. Assefa A, Girma M: Prevalence and antimicrobial susceptibility patterns of Salmonella and Shigella isolates among children aged below five years with diarrhea attending Robe General Hospital and Goba Referral Hospital, South East Ethiopia. Trop Dis Travel Med Vaccines 2019, 5(1):19.

8. Ameya G, Tsalla T, Getu F, Getu E: Antimicrobial susceptibility pattern, and associated factors of Salmonella and Shigella infections among under five children in Arba Minch, South Ethiopia. Annals of Clinical Microbiology and Antimicrobials 2018, 17(1):1.

9. Yildiz C, Öztürk C, Emekdas G: Research of the E. coli 0157: H7 strains cases of the Gastro-enterits. Infeksiyon Dergisi 2005, 19:189-192.

10. Abdullahi M: Incidence and antimicrobial susceptibility pattern of Salmonella species in children attending some hospitals in kano metropolis, kano state-Nigeria. Bayero Journal of Pure and Applied Sciences 2010, 3(1).

11. Shao Y, Zhu S, Jin C, Chen F: Development of multiplex loop-mediated isothermal amplification-RFLP (mLAMP-RFLP) to detect Salmonella spp. and Shigella spp. in milk. International journal of food microbiology 2011, 148(2):75-79.

12. Lauri A, Castiglioni B, Mariani P: Comprehensive analysis of Salmonella sequence polymorphisms and development of a LDR-UA assay for the detection and characterization of selected serotypes. Applied microbiology and biotechnology 2011, 91(1):189-210. 
13. Okeke IN, Klugman KP, Bhutta ZA, Duse AG, Jenkins P, O'Brien TF, Pablos-Mendez A, Laxminarayan R: Antimicrobial resistance in developing countries. Part Il: strategies for containment. The Lancet infectious diseases 2005, 5(9):568-580.

14. Pawlowski SW, Warren CA, Guerrant R: Diagnosis and treatment of acute or persistent diarrhea. Gastroenterology 2009, 136(6):1874-1886.

15. Beyene G, Tasew H: Prevalence of intestinal parasite, Shigella and Salmonella species among diarrheal children in Jimma health center, Jimma southwest Ethiopia: a cross sectional study. Ann Clin Microbiol Antimicrob 2014, 13:10.

16. Pickering LK, Bartlett AV, Woodward WE: Acute infectious diarrhea among children in day care: epidemiology and control. Clinical Infectious Diseases 1986, 8(4):539-547.

17. Girma G: Prevalence, Antibiogram and Growth Potential of Salmonella and Shigella in Ethiopia: Implications for Public Health: A Review. Research Journal of Microbiology 2015, 10(7):288.

18. Wikipedia c: . Awasa. In Wikipedia, The Free Encyclopedia. Retrieved 09:01, November 23, 2019, from. https://enwikipediaorg/w/indexphp?title=Awasa\&oldid=9270298172019, November 19.

19. CLSI C: LSI (2018). Performance Standards for Antimicrobial Susceptibility Testing Clinical and Laboratory Standards Institute.

20. Vargas M, Gascon J, Casals C, Schellenberg D, Urassa H, Kahigwa E, Ruiz J, Vila J: Etiology of diarrhea in children less than five years of age in Ifakara, Tanzania. The American journal of tropical medicine and hygiene 2004, 70(5):536-539.

21. Vandepitte J, Verhaegen J, Engbaek K, Rohner P, Piot P, Heuck C, Heuck C: Basic laboratory procedures in clinical bacteriology: World Health Organization; 2003.

22. Beyene G, Haile-Amlak A: Antimicrobial sensitivity pattern of Campylobacter species among children in Jimma University Specialized Hospital, southwest Ethiopia. Ethiopian Journal of Health Development 2004, 18(3):185-189.

23. Mulatu G, Beyene G, Zeynudin A: Prevalence of Shigella, Salmonella and Cmpylobacter Species and Their Susceptibility Patters Among Under Five Children With Diarrhea in Hawassa Town, South Ethiopia. Ethiopian journal of health sciences 2014, 24(2):101.

24. Terfassa A, Jida M: Prevalence and Antibiotics Susceptibility Pattern of Salmonella and Shigella Species among Diarrheal Patients Attending Nekemte Referral Hospital, Oromia, Ethiopia. International journal of microbiology 2018, 2018.

25. Mamuye Y, Metaferia G, Birhanu A, Desta K, Fantaw S: Isolation and antibiotic susceptibility patterns of Shigella and Salmonella among under 5 children with acute diarrhoea: a cross-sectional study at selected public health facilities in Addis Ababa, Ethiopia. Clinical Microbiology: Open Access 2015.

26. Qu M, Lv B, Zhang X, Yan H, Huang Y, Qian H, Pang B, Jia L, Kan B, Wang Q: Prevalence and antibiotic resistance of bacterial pathogens isolated from childhood diarrhea in Beijing, China (2010-2014). Gut pathogens 2016, 8(1):31.

27. Wilson G, Easow JM, Mukhopadhyay C, Shivananda P: Isolation \& antimicrobial susceptibility of Shigella from patients with acute gastroenteritis in western Nepal. Indian Journal of Medical 
Research 2006, 123(2):145.

28. Lango-Yaya E, Djeintote M, Djimeli C: Contribution to the Study of Antibiotic Resistance on Salmonella and Shigella Strains Isolated in Central African Republic. J Microbiol Exp 2017, 4(1):00105.

29. Akinnibosun F, Nwafor F: Prevalence of diarrhoea and antibiotic susceptibility test in children below $\mathbf{5}$ years at University of Benin Teaching Hospital, Nigeria. International Research Journal of Public and Environmental Health 2015, 2(4):49-55.

30. Hawaz H, Girma S, Tezera Y, Ahmed U, Kelel M: Prevalence and drug susceptibility pattern of Shigella and Salmonella species in under ten diarrhoeic children admitted to Tirunesh-Beijing hospital. International Journal 2017, 3(2):63.

31. Lamboro T, Ketema T, Bacha K: Prevalence and antimicrobial resistance in Salmonella and Shigella species isolated from outpatients, Jimma University Specialized Hospital, Southwest Ethiopia. Canadian Journal of Infectious Diseases and Medical Microbiology 2016, 2016.

32. Mache A: Antibiotic resistance and sero-groups of Shigella among paediatric out-patients in southern Ethiopia. East African medical journal 2001, 78(6):296-299.

33. Roma B, Worku S, Mariam ST, Langeland N: Antimicrobial susceptibility pattern of Shigella isolates in Awassa. Ethiopian Journal of Health Development 2000, 14(2):149-154.

34. Debas G, Kibret M, Biadglegne F, Abera B: Prevalence and antimicrobial susceptibility patterns of shigella species at Felege Hiwot Referral Hospital, Northwest Ethiopia. Ethiop Med J 2011, 49(3):249256.

35. Mekonnen $\mathrm{H}$, Kebede A, Menkir S: Isolation rate and drug resistance patterns of Shigella species among diarrheal patients attending at Hiwot Fana hospital, Harar, Ethiopia. Ethiopian Journal of Science and Technology 2014, 7(1):15-25.

36. Admassu M, Yemane G, Kibret M, Abera B, Nibret E, Adal M: Prevalence and antibiogram of Shigella and Salmonella spp. from under five children with acute diarrhea in Bahir Dar Town. Ethiopian Journal of Science and Technology 2015, 8(1):27-35.

37. Samie A, Guerrant R, Barrett L, Bessong P, Igumbor E, Obi C: Prevalence of intestinal parasitic and bacterial pathogens in diarrhoeal and non-diarroeal human stools from Vhembe district, South Africa. Journal of health, population, and nutrition 2009, 27(6):739.

38. Beyene G, Tasew H: Prevalence of intestinal parasite, Shigella and Salmonella species among diarrheal children in Jimma health center, Jimma southwest Ethiopia: a cross sectional study. Annals of clinical microbiology and antimicrobials 2014, 13(1):10.

39. Saeed A, Abd H, Sandstrom G: Microbial aetiology of acute diarrhoea in children under five years of age in Khartoum, Sudan. Journal of medical microbiology 2015, 64(Pt 4):432.

40. Reda AA, Seyoum B, Yimam J, Andualem G, Fiseha S, Vandeweerd J-M: Antibiotic susceptibility patterns of Salmonella and Shigella isolates in Harar, Eastern Ethiopia. J Infect Dis Immun 2011, 3(8):134-139. 
41. Gebrekidan A, Dejene TA, Kahsay G, Wasihun AG: Prevalence and antimicrobial susceptibility patterns of Shigella among acute diarrheal outpatients in Mekelle hospital, Northern Ethiopia. $B M C$ research notes 2015, 8(1):611.

42. Demissie A, Wubie T, Yehuala FM, Fetene M, Gudeta A: Prevalence and antimicrobial susceptibility patterns of Shigella and Salmonella species among patients with diarrhea attending Gondar Town Health Institutions, Northwest Ethiopia. Sci J Pub Health 2014, 2(5):469-475.

43. Ansari S, Sherchand J, Parajuli K, Mishra S, Dahal R, Shrestha S, Tandukar S, Pokhrel B: Bacterial etiology of acute diarrhea in children under five years of age. Journal of Nepal Health Research Council 2013.

44. Mengistu G, Mulugeta G, Lema T, Aseffa A: Prevalence and antimicrobial susceptibility patterns of Salmonella serovars and Shigella species. J Microb Biochem Technol S 2014, 2:006.

45. Shah M, Kathiiko C, Wada A, Odoyo E, Bundi M, Miringu G, Guyo S, Karama M, Ichinose Y: Prevalence, seasonal variation, and antibiotic resistance pattern of enteric bacterial pathogens among hospitalized diarrheic children in suburban regions of central Kenya. Tropical medicine and health 2016, 44(1):39.

46. Kara TT, Özdemir H, Kurt F, Güriz H, Çiftçi E, Aysev AD, Suskan EZ, Ince E: Prevalence of Salmonella and Shigella spp. and Antibiotic Resistance Status in Acute Childhood Gastroenteritis/Akut Çocukluk Çagi Gastroenteritlerindeki Salmonella-Shigella Sikligi ve Antibiyotik Direnç Durumlari. Cocuk Enfeksiyon Dergisi 2015, 9(3):102.

47. Huruy K, Kassu A, Mulu A, Worku N, Fetene T, Gebretsadik S, Biadglegne F, Belyhun Y, Muche A, Gelaw A: Intestinal parasitosis and shigellosis among diarrheal patients in Gondar teaching hospital, northwest Ethiopia. BMC research notes 2011, 4(1):472.

48. Yismaw O, Negeri C, Kassu A: A five-year antimicrobial resistance pattern observed in Shigella species isolated from stool samples in Gondar University Hospital, northwest Ethiopia. Ethiopian Journal of Health Development 2006, 20(3).

49. Gebreegziabher G, Asrat D, Hagos T: Isolation and antimicrobial susceptibility profile of Shigella and Salmonella species from children with acute diarrhoea in Mekelle Hospital and Semen Health Center, Ethiopia. Ethiopian journal of health sciences 2018, 28(2):197-206.

50. Efuntoye MO, Adenuga A: Shigella Serotypes among nursery and primary school children with diarrhea in Ago-Iwoye and ljebu-Igbo, Southwestern Nigeria. JPCS 2011, 2:29-32.

51. Tiruneh M: Serodiversity and antimicrobial resistance pattern of Shigella isolates at Gondar University teaching hospital, Northwest Ethiopia. Jpn J Infect Dis 2009, 62(2):93-97.

52. Asrat D: Shigella and Salmonella serogroups and their antibiotic susceptibility patterns in Ethiopia. 2008.

53. Mama M, Alemu G: Prevalence, antimicrobial susceptibility patterns and associated risk factors of Shigella and Salmonella among food handlers in Arba Minch University, South Ethiopia. BMC infectious diseases 2016, 16(1):686. 


\section{Tables}

Table 1

\begin{tabular}{|c|c|c|c|c|c|c|c|c|c|c|c|}
\hline \multirow{3}{*}{ Antibiotics } & \multicolumn{11}{|c|}{ Isolates } \\
\hline & \multicolumn{3}{|c|}{ S. typhi(1) } & \multicolumn{2}{|c|}{ Shigella spp(9) } & \multicolumn{3}{|c|}{$\begin{array}{l}S_{\text {(11) }} \text { dysentery } \\
\text { tis }\end{array}$} & \multicolumn{3}{|c|}{ Total (21) } \\
\hline & $\mathrm{S}$ & $\mathrm{R}$ & $\mathrm{S}$ & I & $\overline{\mathrm{R}}$ & $\mathrm{S}$ & I & $\mathrm{R}$ & $\mathrm{S}(\%)$ & I (\%) & $\mathrm{R}(\%)$ \\
\hline AMP & 0 & 1 & 0 & 4 & 5 & 0 & 2 & 9 & $0(0.0)$ & $6(28.6)$ & $15(71.4)$ \\
\hline COT & 1 & $\begin{array}{c}- \\
\end{array}$ & 5 & 0 & 4 & 5 & 3 & 3 & $11(52.4)$ & $3(14.3)$ & $7(33.3)$ \\
\hline CIP & 1 & - & 9 & 0 & 0 & 10 & 1 & 0 & $20(95.2)$ & $1(4.8)$ & $0(0.0)$ \\
\hline $\mathrm{CRO}$ & 1 & 0 & 9 & 0 & 0 & 8 & 0 & 3 & $18(85.7)$ & $0(0.0)$ & $3(14.3)$ \\
\hline CAZ & 1 & 0 & 7 & 1 & 1 & 10 & 1 & 0 & $18(85.7)$ & $2(9.5)$ & $1(4.8)$ \\
\hline GEN & 1 & 0 & 5 & 4 & 0 & 11 & 0 & 0 & $17(81.0)$ & $4(19.0)$ & $0(0.0)$ \\
\hline CAF & 1 & 0 & 7 & 1 & 1 & 8 & 2 & 1 & $16(76.2)$ & $3(14.3)$ & $2(9.5)$ \\
\hline CRX & 1 & 0 & 6 & 2 & 1 & 7 & 1 & 3 & $14(66.7)$ & $3(14.3)$ & $4(19.0)$ \\
\hline AUG & 0 & 1 & 1 & 4 & 4 & 0 & 3 & 8 & $1(4.8)$ & $7(33.7)$ & $13(61.9)$ \\
\hline TAT & 0 & 1 & 0 & 5 & 4 & 0 & 3 & 8 & $0(0.0)$ & $8(38.1)$ & $13(61.9)$ \\
\hline
\end{tabular}

Table 2 


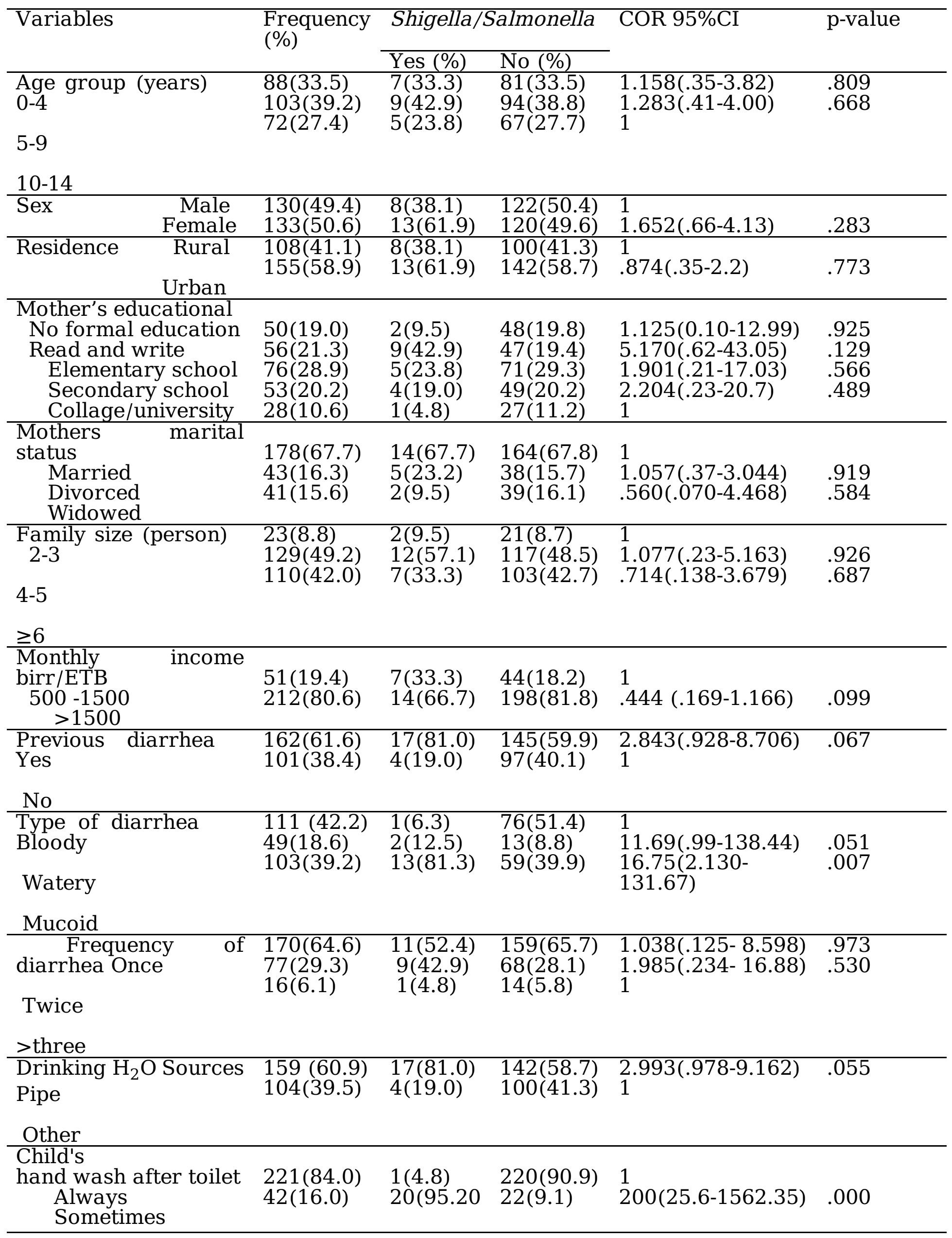


Food has taken before illness Cooked food Overnight food Raw vegetable $82(31.2) \quad 5(23.8)$ 77(29.3) 8(38.1) $64(24.3) \quad 5(23.8)$ $40(15.2) \quad 3(14.3)$

$77(31.8)$

$.801(.182-3.533)$

$69(28.5) \quad 1.430(358-5.716) \quad 613$

5924.4) $\quad 1.045(.236-4.634) \quad .954$

Raw milk

Storage of cooked food

Open containers

40(15.2) $\quad 16(76.2) \quad 24(9.9)$

223(84.8)

$5(23.8)$ 218(90.1)

$29.1(9.78-86.372) \quad .000$

Closed containers

\begin{tabular}{|c|c|c|c|c|c|}
\hline $\begin{array}{l}\text { Hand washing before } \\
\& \text { after a meal } \\
\text { Yes } \\
\text { No }\end{array}$ & $\begin{array}{l}85(32.3) \\
178(67.7)\end{array}$ & $\begin{array}{l}6(28.6) \\
15(71.4)\end{array}$ & $\begin{array}{l}79(32.6) \\
160(66.1)\end{array}$ & $\begin{array}{l}1 \\
1.212(.453-3.242)\end{array}$ & .702 \\
\hline \\
\hline $\begin{array}{l}\text { of cooking containers } \\
\text { Always } \\
\text { Sometimes }\end{array}$ & $\begin{array}{l}157(59.7) \\
106(40.3)\end{array}$ & $\begin{array}{l}4(19.0) \\
17(81.0)\end{array}$ & $\begin{array}{l}153(63.2) \\
89(36.8)\end{array}$ & $\begin{array}{l}1 \\
7.306(2.38-22,4)\end{array}$ & 001 \\
\hline Malnutrition & $25(9.5)$ & $3(14.3)$ & $22(9.1)$ & 1 & \\
\hline Yes & $238(90.5)$ & $18(85.7)$ & $220(90.9)$ & $1.67(.46-6.121)$ & .441 \\
\hline \multicolumn{6}{|l|}{ No } \\
\hline $\begin{array}{l}\text { Vaccination } \\
\text { Yes }\end{array}$ & $\begin{array}{l}202(76.8) \\
61(23.2)\end{array}$ & $\begin{array}{l}14(66.7) \\
7(33.3)\end{array}$ & $\begin{array}{l}188(77.7) \\
54(223)\end{array}$ & $i^{.574(.221-1.495)}$ & .256 \\
\hline \multicolumn{6}{|c|}{ No } \\
\hline $\begin{array}{l}\text { Contact with animals } \\
\text { Yes }\end{array}$ & $\begin{array}{l}137(52.1) \\
126(47.9)\end{array}$ & $\begin{array}{l}13(61.9) \\
8(38.1)\end{array}$ & $\begin{array}{l}124(51.2) \\
118(48.8)\end{array}$ & $\begin{array}{l}1.546(.62-3.865) \\
1\end{array}$ & .351 \\
\hline No & & & & & \\
\hline
\end{tabular}

Table 3 


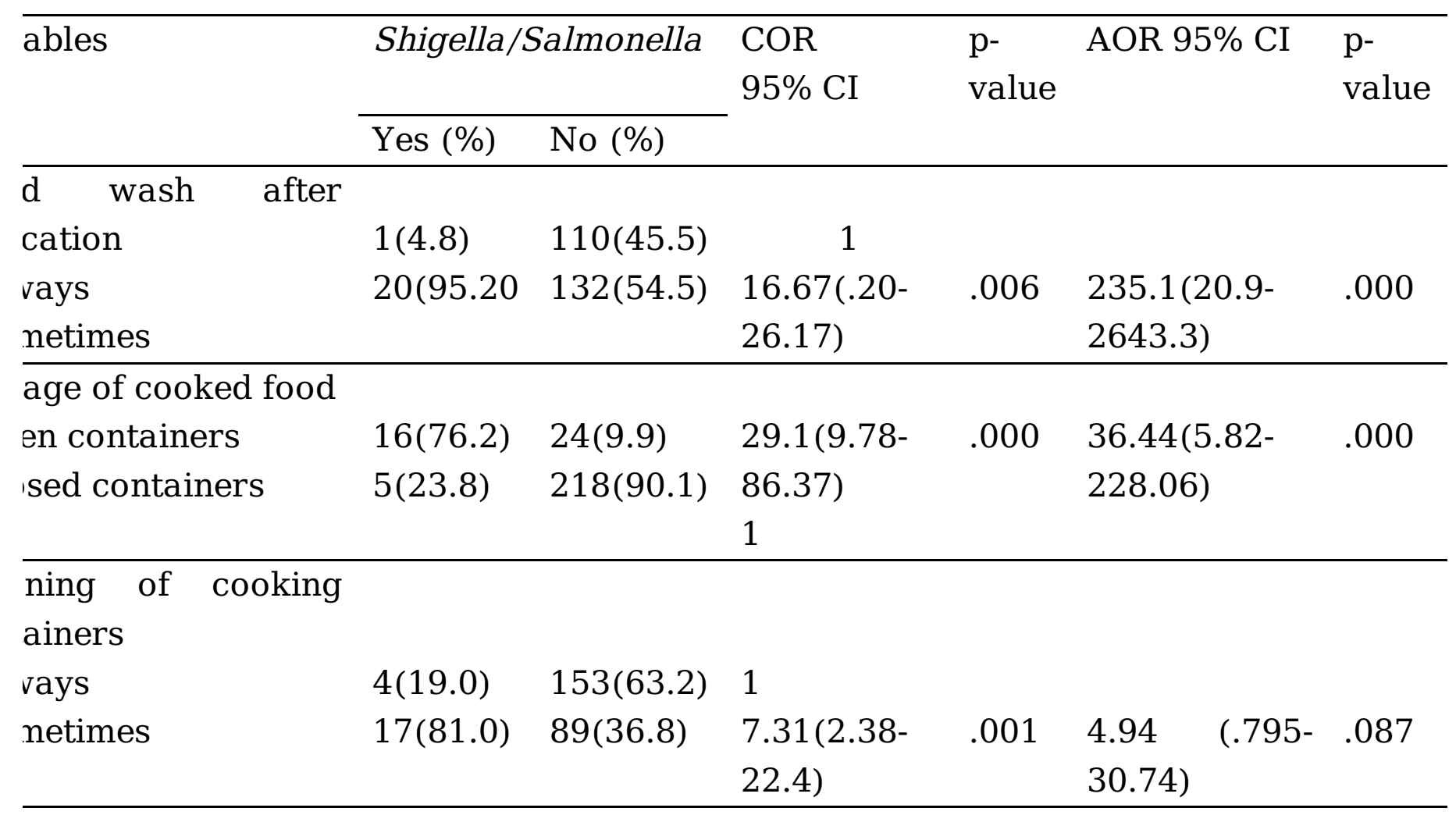

\section{Figures}

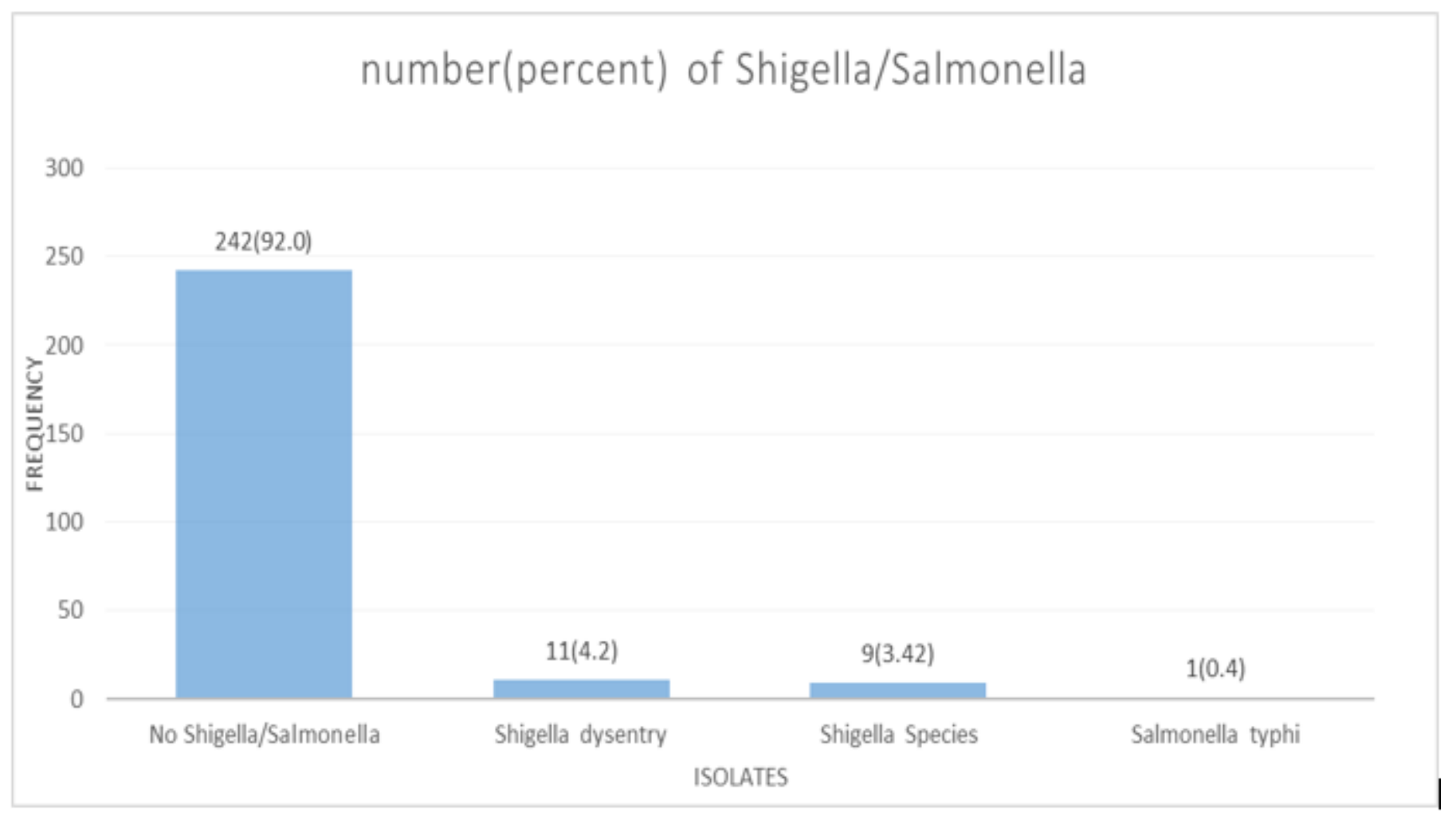

Figure 1 
Magnitude of Shigella Spp, Shigella dysentery and Salmonella typhi in diarrheic pediatrics patients from Alamura Health Center, southern Ethiopia, 2019. 